\title{
A comunicação popular como ferramenta para a construção da cidadania
}

\section{Cristiane Reimberg}

\section{Resumo:}

A comunicação popular deve contribuir para a construção da cidadania na comunidade. Segundo PERUZZO (1991), essa é uma comunicação emergente que vem do povo ou tem a ver com ele. É a partir desse conceito que refletimos sobre o papel desse tipo de comunicação para o conhecimento de direitos e deveres e para a prática da cidadania. Também analisamos como essa comunicação, que valoriza a comunidade, pode acontecer em uma sociedade de massa, fazendo uma relação com o jornalismo. Nesse sentido, utilizamos HELLER (1989) como fonte sobre a comunidade e a prática cotidiana. Já em relação ao jornalismo, teremos como base GENTILLI (2005). A questão da cidadania, por sua vez, será abordada a partir de MANZINI-COVRE (1993), que mostra a cidadania como o próprio direito à vida em sentido pleno, um direito que deve ser construído coletivamente.

\section{Palavras Chave:}

Comunicação Popular; Cidadania; Jornalismo.

\section{Abstract:}

The popular communication should contribute to the construction of citizenship in the community. According PERUZZO (1991), this is an emergent communication that comes from people or is related to him. It's from this concept that we reflect about the role of this communication to the knowledge of rights and duties and the practice of citizenship. Also we analyze how this communication, which values the community, can happen in a society of mass, making a relationship with journalism. So we use HELLER (1989) to talk about community and daily practice. In relation to journalism, we based on GENTILLI (2005). The issue of citizenship, in turn, will be portrayed from MANZINI-COVRE (1993), which shows the citizenship as the right to life in the full sense, a right that must be collectively constructed.

\section{Keywords:}

Popular Communication, Citizenship, Journalism.

\section{Comunicação Popular: o povo como protagonista}

A comunicação popular, segundo PERUZZO (1991), é uma comunicação emergente que vem do povo ou tem a ver com ele. O povo aparece como protagonista, mesmo que não na totalidade, de novas práticas sociais, culturais e políticas.

É necessário levar em consideração que por comunicação popular se pode compreender processos comunicativos variados porque na realidade ela é exatamente isso. Ela vai de pequenos veículos de comunicação dirigida, à comunicação grupal e até perpassa espaços nos meios massivos, como dos veículos orais, impressos, visuais e audiovisuais. E ainda por se realizar com metodologias não uniformes. Umas são participativas, outras permanecem no esquema de serem espaço ocasional para a "voz do povo", outras nem chegam a isso, se constituindo em práticas até autoritárias de comunicação. (PERUZZO, 1991,p.70) 
PERUZZO (1998,p.119) relaciona a comunicação popular com os movimentos sociais, classificando-a como "popular-alternativa". É a comunicação na luta por melhores condições de existência para o povo, mediante movimentos de base organizados. Essa corrente se posiciona de dois modos diferentes. Uma surgida em 80, denominada como "populista esquerdizante", que concebe a comunicação popular como libertadora e crítica, capaz de levar à transformação social através de conteúdos críticos e reivindicatórios, colocada em antagonismo à comunicação de massa..

A outra vertente aparece no início dos anos 90 e tem uma posição mais dialética e flexível, já que acredita que a comunicação popular pode contribuir para a democratização dos meios de comunicação e da sociedade. Ela percebe que não consegue levar a uma transformação imediata devido às limitações, contradições e sua inserção na grande diversidade cultural. Além disso, não se contrapõe à comunicação de massa.

Essas duas linhas de pensamento coexistem. A autora ainda complementa que a "comunicação popular alternativa" é uma realização da sociedade civil que se constitui historicamente, podendo sofrer transformações e ocupar novos espaços e tecnologias de informação como rádio, TV e Internet.

Já FESTA (1986,p.10) afirma que a comunicação popular no Brasil nasce no movimento operário através da imprensa sindical e que chega ao campo através da Comissão Pastoral da Terra, de centros de educação popular e de sindicatos. Ainda aponta a importância das Comunidades Eclesiais de Base (CEBs), que nos anos 60 e 70 se multiplicaram pelo país. É a partir delas que surgem movimentos sociais e se dá a participação das mulheres nos mesmos. As CEBs se fundamentaram na Teologia da Libertação - que indica a opção pelos pobres, em Gramsci - como ferramenta teórica para a construção de uma nova hegemonia cultural e política e em Paulo Freire - como aplicação metodológica (FESTA, 1984,p.73). Também foram espaços para o desenvolvimento de uma comunicação popular, pois privilegiavam "a fala, a relação interpessoal, a formação de seus participantes a partir da convivência fraterna e cotidiana".

É importante salientar que a comunicação popular não se restringe a meios e técnicas, mas também a processos culturais que se articulam através de redes populares com sentidos e símbolos sociais e políticos diferenciados da classe dominante. Ela constitui a busca de outra sociedade a partir das organizações sociais (1984,p.232).

Em suma, a comunicação popular refere-se ao modo de expressão das classes populares de acordo com a sua capacidade de atuar sobre o contexto social na qual ela se reproduz. Contexto de enfrentamento com o projeto de dominação capitalista. Nesse contexto, a comunicação popular é o agente da definição do projeto popular, que vai conformando a inter-relação entre grupos e classes populares e a sua incapacidade atual de articular alianças políticas. Daí porque ela se expressa em espaços determinados como nas CEBs, sindicatos, grupos de mulheres, centros de educação e comunicação popular, grupos culturais, movimento de favelados, etc. (FESTA, 1984,p.170)

Percebe-se, segundo PERUZZO (1998,p.122), que essa comunicação popular pode ser compreendida por diversos processos, já que não há uma uniformidade metodológica na execução dessa comunicação e na produção de seus veículos. Enquanto alguns abrem espaço para que realmente haja uma comunicação participativa, outros só o fazem ocasionalmente e ainda há aqueles que nem chegam a fazê-lo. É necessário, assim, que se promova a participação de maneira mais ampliada, já que muitas vezes elas ficam restritas a algumas lideranças (1998,p.143). 


\section{Comunidade: o espaço para a comunicação popular}

As comunidades são os espaços propícios para a realização da comunicação popular. Sejam como receptoras da mensagem, sejam como construtora da mesma. A comunicação popular seria uma alternativa para informar as comunidades sobre a questão da cidadania. Mas em um contexto de globalização e de sociedade de massas em que vivemos, o que seriam as comunidades?

A comunidade é uma unidade estruturada, organizada, de grupos, dispondo de uma hierarquia homogênea de valores e à qual o indivíduo pertence necessariamente, essa necessidade pode decorrer do fato de se 'estar lançado' nela ao nascer, caso em que a comunidade promove posteriormente a formação da individualidade ou de uma escolha relativamente autônoma do indivíduo já desenvolvido. (HELLER, 1989,p.70-71)

HELLER (1989) faz uma diferenciação entre grupo e comunidade. A relação entre indivíduo e grupo pode se basear na casualidade. No entanto, quando os fatores deixam de ser casuais, na medida em que a individualidade constrói os grupos a que se pertencem, esses grupos se convertem em comunidades.

O pertencimento a uma comunidade pode acontecer em conseqüência de uma necessidade exterior, segundo a autora. Mas também pode partir de uma necessidade interna, uma escolha individual. Antes da sociedade burguesa, as comunidades eram naturais. Não podiam ser objeto de uma escolha livre. As possibilidades de individualidade e hierarquia de valores eram determinadas no nascimento. Com a burguesia, são abolidas as comunidades naturais como integrações sociais primárias. Nasce a possibilidade de escolher a integração. É possível "não se tornar indivíduo mediante a nossa comunidade, mas ser capaz de escolher uma comunidade graças ao fato de já ser indivíduo" (HELLER, 1989,p.68).

A sociedade burguesa separou o fato de pertencer a uma classe e o fato de pertencer a uma comunidade. O homem se converteu em um ser social não necessariamente comunitário. Não é obrigatório pertencer a uma comunidade assim como a existência individual não está determinada pela existência social. E quando se pertence a uma comunidade, trata-se de uma comunidade construída, que foi escolhida livremente.

As comunidades organizadas tendo em vista determinados fins históricos solicitam sobretudo determinadas capacidades dos indivíduos. Por isso, os indivíduos cujas capacidades inatas são congruentes com as qualidades mais importantes para as metas de uma comunidade têm maiores possibilidades de desenvolver sua individualidade do que aqueles cujas capacidades e talentos inatos estão fora de tal tendência. Portanto, dois motivos podem estar na base da escolha de comunidade: o valor axiológico objetivo da comunidade, seus momentos favoráveis à essência humana; e a intenção de explicitar nela e através dela a própria individualidade. (HELLER, 1989,p.79)

Isso significa que o conteúdo axiológico desse indivíduo se manifestará no conteúdo axiológico da comunidade por ele escolhida, ou seja, eles têm os mesmos valores. Assim, segundo HELLER (1989), o conteúdo axiológico da comunidade ganha legitimidade através da individualidade. Já uma comunidade com conteúdo axiológico negativo não desenvolverá a individualidade nem o valor do indivíduo. Quando ocorre o contrário e se encontra uma comunidade com conteúdo axiológico positivo, há o cenário para que a individualidade se desenvolva.

Como vimos, a comunidade é o espaço ideal para que se desenvolva a comunicação popular. No entanto, a sociedade atual pode ser definida como uma sociedade de massas. Para HELLER (1989,p.84), a sociedade de massas impossibilita a decisão individual, sem a qual não pode haver comunidade. "A massa é co-participação de muitos homens numa ação determinante". Dessa forma, um grupo ou comunidade jamais pode ser uma massa. Isso porque estão sempre articulados e estratificados, ao contrário da massa, que "pode perfeitamente 
aparecer não-estratificada e não-articulada" (HELLER, 1989,p.69).

A sociedade de massa favorece

a estrutura interna na qual não se podem desenvolver nem a individualidade, nem a comunidade; a sociabilidade dos homens, então, passa a expressar-se desde o primeiro momento como se todos formassem uma multidão manipulada e como se por todos os lados dominasse uma atitude de dispersão. 'Sociedade de massas', portanto, é uma expressão metafórica para descrever uma sociedade conformista manipulada. (HELLER, 1989,p.70)

Mas nem todos têm uma visão negativa da sociedade de massas. Para GENTILLI (2005,p.28), nela há a possibilidade de "participação ampla de todos os homens na vida social cotidiana, à emersão de uma massa de sujeitos que passa a desfrutar da possibilidade potencial de acesso ou fruição a bens (materiais ou culturais) ou a direitos antes apenas privilégio das elites". Por outro lado, o autor acredita que esses mecanismos de inclusão são perversos. O que não impede que ele defenda a possibilidade de uma democracia de massas, que conta com a contribuição do jornalismo para o exercício do direito de informação do cidadão.

Acreditamos que apesar da possibilidade de aniquilamento das comunidades pela sociedade de massa, as comunidades sobrevivem. Um indivíduo pode ao mesmo tempo em que está inserido na massa em determinadas situações, ser membro ativo de uma comunidade em outras. Nesse cenário, o jornalismo contribuiria cumprindo seu papel de informar sobre questões de cidadania. Mas esse papel não é exclusivo do jornalismo, que muitas vezes deixa essa questão de lado. É essencial que a comunicação popular esteja engajada em informar suas comunidades sobre direitos e deveres, contribuindo para a construção da cidadania.

Para PERUZZO (1998,p.130-132), a comunicação popular e a comunicação massiva não são excludentes e sim complementares. Além do que, os meios de comunicação popular não são forças que superam os meios massivos, apesar de sua importância política. No entanto, a mídia não consegue suprir a necessidade das comunidades e dos movimentos sociais em termos de comunicação. O que ocorre é que apesar de seu poder de manipulação e de estar a serviço dos interesses da classe dominante, ela também contribui para a sociedade e para o interesse público. Além disso, a comunicação popular também pode se valer deles. Inclusive, um ponto que a autora observa é que a comunicação popular poderia usar melhor um recurso da mídia massiva, que é o entretenimento, o lúdico e o humor, aliando isso aos valores culturais de onde estão inseridos.

Essa postura de opor os meios populares massivos sofreu uma profunda revisão nos anos noventa, em função das mudanças que ocorrem na sociedade. Apesar de serem campos de conflitos e terem suas especificidades, sob a ótica do receptor não se estabelece esse antagonismo. Por outro lado, muitas das metas e linguagens antes restritas ou acessíveis apenas aos meios alternativos começaram a ser incorporadas na programação da mídia convencional, seja por iniciativa desta ou por pressão de organizações da sociedade civil. Além do que, entidades e grupos dos movimentos populares passaram a ocupar espaços nos grandes veículos, para transmitir suas mensagens e os programas por eles produzidos, e mesmo a deter a posse de canais de comunicação como jornais e rádios de alcance local ou até regional. (PERUZZO,1998,p.132)

Uma experiência que temos observado é o uso da comunicação pela Pastoral da Criança. A organização tem um jornal mensal com 280 mil exemplares, que são distribuídos para seus voluntários em todo o Brasil. A publicação tem um espaço, que geralmente ocupa metade do veículo, para publicar as notícias enviadas pelas comunidades. Nas outras páginas, são recorrentes textos sobre saúde, direitos e o papel de cada um frente à cidadania. $\mathrm{O}$ jornal funciona como uma forma da comunidade se ver e ao mesmo tempo aprender mais para desenvolver suas atividades, sendo usados até mesmo para discussões em reuniões. 
A organização também produz programas de rádio semanais voltados para saúde e educação, possui guias que orientam as atividades e realizam diversas formações. Segundo dados de 2007 da própria entidade, ela acompanha uma média mensal de 1.816.261 crianças menores de 6 anos e 94.987 gestantes. Esse trabalho é feito em 4.066 municípios por 261.962 voluntários, que visitam as famílias e levam orientações sobre saúde. A entidade age em prol da redução da mortalidade infantil, da saúde da criança e tem atividades paralelas, como alfabetização e programas de geração de renda.

Nesse processo, percebemos uma busca pelo alargamento da cidadania e que é impulsionada pela comunicação popular. PERUZZO (1998,p.302), em relação aos movimentos sociais, afirma que a comunicação popular surge "como uma necessidade e se realiza articulada às práticas sociais. Ela contribui com maior ou menor intensidade para a democracia, dependendo dos instrumentos, das formas e da metodologia que utiliza".

GENTILLI (2005), por sua vez, acredita que o jornalismo supera a mercadoria, típica da sociedade de massa e da indústria cultural, contribuindo para a construção da cidadania. Isso porque a informação jornalística pode possibilitar que as pessoas ajam como cidadãs, saindo da condição de massa. O jornalismo deve oferecer "informações que o cidadão tem o direito de receber para que possa exercer plenamente todos os seus direitos".

Devemos estender a definição acima também para a comunicação popular, que também tem o dever de informar o cidadão para que ele exerça seus direitos. A diferença entre eles é a de que o jornalismo faz isso no âmbito das massas. Já a comunicação popular faz no âmbito das comunidades, contando até com a participação das mesmas na elaboração das notícias.

Os jornais, para o autor, são vistos como "organizações voltadas para a produção de informação pública", e o direito à informação pública constitui um direito de cidadania. Quando esse direito não é cumprido, os outros direitos ficam prejudicados.

Nas democracias de massas, marcadas pela expansão de direitos, o direito à informação constitui-se num direito 'em si' e ao mesmo tempo é a porta de acesso a outros direitos. Neste sentido, a informação, conforme seja a necessidade que dela se tenha pode ser entendida como direito social, como direito civil e como direito político. (GENTILLI, 2005,p.24)

\section{O percurso da cidadania}

O jornalismo e a comunicação popular podem estimular a construção da cidadania, ao informar os cidadãos sobre seus direitos. Mas nem sempre a cidadania teve o destaque de hoje. LIMA afirma que por muito tempo ela esteve longe dos debates acadêmicos, começando a aparecer com a Constituição Cidadã de 1988. MANZINI-COVRE (1993) relata que nos anos 60 e 70 a cidadania tinha uma conotação pejorativa, associada à democracia americana.

Para MANZINI-COVRE (1993), cidadania é o próprio direito à vida em sentido pleno, um direito que deve ser construído coletivamente. Assim, ser cidadão significa ter direitos e deveres. Vai muito além do direito de votar, por exemplo, que deve vir acompanhado de condições econômicas, políticas, sociais e culturais. Nesse sentido, a Constituição é um recurso para os cidadãos encaminharem e conquistarem propostas mais igualitárias.

Só existe cidadania se houver a prática da reivindicação, da apropriação de espaços, da pugna para fazer valer os direitos do cidadão. Nesse sentido a prática da cidadania pode ser a estratégia, por excelência para a construção de uma sociedade melhor. Mas o primeiro pressuposto dessa prática é que esteja assegurado o 
direito de reivindicar os direitos, e que o conhecimento deste se estenda cada vez mais a toda população. (...) Em vez de meros receptores, são acima de tudo sujeitos daquilo que podem conquistar. Se existe um problema em seu bairro ou em sua rua, por exemplo, não se deve esperar que a solução venha espontaneamente. É preciso que os moradores se organizem e busquem uma solução capaz de atingir vários níveis, entre eles o de pressionar os órgãos governamentais competentes (MANZINI-COVRE, 1993,p.10)

A cidadania, explica a autora, contempla direitos civis, sociais e políticos. Os civis são os direitos de se dispor do próprio corpo. Eles dependem da existência dos direitos políticos, que por sua vez, dependem de um regime democrático. Já os direitos sociais são aqueles que tratam do atendimento das necessidades humanas básicas como alimentação, habitação, saúde e educação. Muitas vezes são usados pelos detentores do poder para administrar a classe trabalhadora, que deve saber ocupar os espaços acenados para reverter esse quadro. Já os direitos políticos abordam a deliberação do homem sobre sua vida, o direito da livre expressão do pensamento, da prática política, religiosa. Eles se relacionam com a convivência com outros homens em organismos de representações e deliberação dos direitos sociais e civis.

O jornalismo e, no nosso entendimento, a comunicação popular podem contribuir nessas três dimensões de direitos:

um jornalismo produzido em condições de oferecer, da melhor maneira possível, uma forma de conhecimento do mundo, que permita ao cidadão as condições de escolha quando se tratar de direitos políticos, que ofereça as informações básicas (jornalismo de serviços) para o desenrolar o cotidiano de suas atividades, que pense a práxis profissional no contexto amplo da ampliação da cidadania, do pluralismo, da liberdade, da democracia. (GENTILLI, 2005,p.143)

Ao pensar a cidadania, também é necessário rever a sua trajetória ao longo da história e os sentidos que o termo foi adquirindo. MANZINI-COVRE (1993) destaca que a cidadania se desenvolve com o capitalismo e a visão burguesa. A valorização do trabalho, que vem com a ética protestante, foi o primeiro marco para a existência da cidadania. A Igreja Católica deixa o centro do poder. Valoriza-se a racionalidade dos homens, que são iguais pelo trabalho e pela capacidade que têm. É uma visão burguesa que preza o individualismo e um tipo de cidadania.

Assim, quando a burguesia deixa de ser revolucionária para assumir o poder, vincula os direitos humanos aos que têm propriedade. É dessa forma que se explica a dominação da burguesia. Já uma cidadania mais efetiva, estende os direitos a todos. No entanto, para a autora, a cidadania não é uma categoria estritamente burguesa. Ela pode ser apropriada pelos trabalhadores, que devem usar os poderes executivo, legislativo e judiciário, assim como os meios de comunicação, para construir a cidadania e estendê-la a todos.

O marxismo também contribuiu para a construção do conceito de cidadania ao criticar o uso dos direitos pela burguesia para dominar grupos. A força de trabalho, por exemplo, serve para pressionar e fazer valer os direitos. Ela ainda aponta as características do que seria a cidadania plena, que vem sendo ameaçada por um conceito mais esvaziado e apoiado no consumismo e imobilismo.

Não pode haver cidadania se não houver um salário condigno para a grande maioria da população. O Trabalhador, enquanto mercadoria, deve lutar para obter certa equivalência na troca estabelecida com o capitalista e o Estado. É preciso que ele tenha acesso aos bens que complementam sua vida (habitação, saúde e educação) e que compõem os chamados direitos sociais. Mas, antes é necessário que os trabalhadores tenham direitos políticos, e que existam mínimas condições democráticas para reivindicar o seu direito de ser cidadão e de, enquanto e tal, poder batalhar, por quaisquer de seus direitos. Por outro lado, é preciso que esses trabalhadores possam ser educados sobre a existência desses direitos, vendo dessa forma a amplidão do que há 
para construir em termos de uma sociedade sempre melhor. (MANZINI-COVRE, 1993,p.37)

A cidadania traz consigo o sentido de sociedade civil, na qual se reconhece o outro como sujeito de direitos legítimos. Isso é resultado de lutas sociais de movimentos e organizações nos anos 70 e 80 . Já nos anos 90 , esses espaços são estimulados por ONGs cidadãs, que consistem em ser entidades sem fins lucrativos que promovem e desenvolvem comunidades carentes a partir de relações de direitos e deveres da cidadania. (GOHN, 1997,p.302-303)

Outro fator a ser considerado é que as agendas dos órgãos públicos contemplam a interação com a sociedade civil. No entanto, essa interação ocorre segundo interesses das elites ou dos grupos que estão no poder. (GOHN, 1997,p.318)

A partir do início dos anos 90, o uso do termo "cidadania" se difundiu cada vez mais pela sociedade brasileira. Enquanto a noção redefinida continuou subjacente às lutas populares e às práticas políticas de partidos políticos como o PT, e ONGs como as congregadas na Associação Brasileira de Organizações Não Governamentais (ABONG), a cidadania esteve também por trás de campanhas de solidariedade voltadas para a mobilização da classe média, tais como a Ação da Cidadania contra a Fome, liderada por Hebert de Souza (Betinho), ou as associações de empresários progressistas, tais como a CIVES (Associação Brasileira de Empresários pela Cidadania). Essa difusão se acentua ao longo da década e hoje a apropriação do termo cidadania se generalizou, com sentido e intenções obviamente muito diferentes. (DAGNINO, 2000,p.84)

O exercício da cidadania passa a ser pensado de forma coletiva através de grupos e instituições que se legitimaram juridicamente a partir de 88. Não se trata mais de reivindicar, pressionar ou demandar. É a hora de fazer, de propor, de participar qualificadamente. A exclusão social também ganha nova roupagem no período com a violência generalizada, a desagregação da autoridade estatal e o surgimento de estruturas paralelas de poder. Esses pontos acabam tendo efeito sobre as estruturas organizativas da população. (GOHN, 1997,p.288)

DAGNINO (1994) procura aliar os movimentos sociais à cidadania. A noção de cidadania, segundo a autora, emerge a partir dos anos 80 e está ligada à experiência dos movimentos sociais, que por sua vez, também contribuiu para a construção da democracia. A partir dessa movimentação, aparecem novos atores sociais e direitos. Surge a concepção do "direito a ter direitos" (Hannah Arendt) e é visível a luta dos excluídos pelo sistema econômico:

A nova cidadania, ao contrário da concepção liberal, não se vincula a uma estratégia das classes dominantes e do Estado para a incorporação política progressiva dos setores excluídos, com vistas a uma maior integração social, ou como condição jurídica e política indispensável à instalação do capitalismo. A nova cidadania requer (e até pensada como sendo esse processo) a constituição de sujeitos sociais ativos, definindo o que eles consideram ser os seus direitos e lutando pelo seu reconhecimento. Nesse sentido, ela é uma estratégia dos não-cidadãos, dos excluídos, uma cidadania 'de baixo para cima'. (DAGNINO, 1994,p.108)

A experiência dos movimentos sociais é fundamental para essa construção da cidadania. "Na organização desses movimentos sociais, a luta por direitos - tanto o direito à igualdade como direito à diferença constituiu a base fundamental para a emergência de uma nova noção de cidadania”. Essa noção organiza a construção de uma cultura democrática. (DAGNINO, 1994,p. 104)

Também na América Latina a experiência dos movimentos sociais está levando a uma redefinição no que se entende por cidadão, não apenas em relação aos direitos à diferença. Isto implicaria uma perda de substância no conceito de cidadania manipulado por juristas: mais do que como valores abstratos, os direitos são importantes como algo que se constrói e muda com as práticas e discursos. A cidadania e os direitos não 
falam unicamente da estrutura formal de uma sociedade; indicam, além disso, o estado da luta pelo reconhecimento dos outros como sujeitos de "interesses válidos, valores pertinentes e demandas legítimas". Os direitos são reconceitualizados como "princípios reguladores das práticas sociais, definindo as regras das reciprocidades esperadas na vida em sociedade através da atribuição mutuamente consentida (e negociada) das obrigações e responsabilidades, garantias e prerrogativas de cada um”. (CANCLINI, 2005:36)

MANZINI-COVRE (1993), por sua vez, destaca que os movimentos sociais são espaços para lutas que ampliarão a cidadania da população carente. No entanto, é preciso estar atento. As organizações podem ter seus interesses originais desvirtuados. Sindicatos que deviam lutar pelos trabalhadores, passam a geri-los. Um exemplo é o sindicalismo de resultado.

As organizações podem ainda ser cooptadas por partidos políticos. Se respeitarem os movimentos e o diálogo, os partidos podem ajudar as organizações a serem efetivas. O problema é quando passam a manipular o movimento e usá-lo para interesses partidários. Os canais de representação, como sindicatos e partidos, devem atuar em prol dos interesses coletivos dos representados.

Diante desse cenário, os sujeitos devem agir e lutar por seus direitos. Esse é o pressuposto básico para a cidadania.

Em suma, insisto sobre os contornos da cidadania plena. O primeiro passo é aquela revolução interna, na qual o rompimento com o autoritarismo e com o consumismo começa em cada uma das subjetividades - em cada um de nós, portanto, a todo momento - e da qual extraímos a força subjetiva de se sobrepor ao cotidiano e, pouco a pouco, ao mundo, ao capitalismo. Externamente em termos da sociedade global, devem ser mantidas as condições mínimas de democracia como espaço para avançar. Então, torna-se possível o desenvolvimento daquela ação social de conteúdo coletivo dos trabalhadores, no campo econômico, para obter os bens e direitos a que fazem jus. E também, o exercício da ação social no nível político, como construção da democracia em seu sentido mais amplo - de uso da persuasão, do argumento, de construção da justiça, liberdade, igualdade. (MANZINI-COVRE, 1993,p.74)

Já para CANCLINI (2005,p.36), a cidadania deve ser repensada como "estratégia política". Essa postura implica em "reivindicar os direitos de aceder e pertencer ao sistema sócio-político como o direito de participar na reelaboração do sistema, definindo portanto aquilo de que queremos fazer parte". A cidadania passa a envolver não só a questão dos direitos como também das responsabilidades e do pertencimento. Não são apenas os direitos políticos, civis e sociais que contam, mas também o direito à individualidade: "os desejos do indivíduo enquanto sujeito". A cidadania é conquista de espaço. (FAXINA, 2001,p.76-90)

A afirmação de FAXINA (2001) vai de encontro com MANZINI-COVRE (1993,p.63-66), para quem a cidadania depende da ação dos sujeitos e dos grupos nos quais os mesmos estão inseridos, além das condições globais da sociedade. A "revolução" por uma sociedade melhor passa pela subjetividade das pessoas. É necessário agir com a consciência de que a democracia se constrói a todo instante nas relações sociais. "É preciso criar espaços para reivindicar os direitos, mas é preciso também estender o conhecimento a todos, para que saibam da possibilidade de reivindicar".

A criação desses espaços passa pela comunicação. GENTILLI (2005) defende que o cidadão precisa ter acesso à informação pública e que essa é uma condição para a ampliação de seus direitos. Claro que a falta de democratização da mídia, a face industrial da produção da notícia e o alcance limitado da comunicação popular devem ser considerados, mas isso não deve impedir que se trabalhe em prol do direito da informação e contra essas estruturas limitantes.

É preciso que o jornalismo cumpra seu dever de informar e que o cidadão tenha o direito de informação. Essa 
função também deve ser cumprida pela comunicação popular. Assim, os cidadãos serão informados sobre seus direitos civis, políticos e sociais, e poderão exercer seus direitos de cidadania. A informação sobre os direitos é matéria-prima para que se realize uma cidadania ativa e se chegue à revolução interna de que fala MANZINI-COVRE (1993). Essa revolução interna possibilitará a cidadania plena e vai de encontro com a reflexão de HELLER (1989,p.117) sobre um pensamento de Marx:

Marx disse que, transformando o mundo, os homens se transformam a si mesmos. Não modificaremos substancialmente o seu pensamento se alterarmos sua frase e afirmarmos agora que não podemos transformar o mundo se, ao mesmo tempo, não nos transformarmos a nós mesmos.

Essa transformação deve alcançar espaço na nossa vida cotidiana, como defende HELLER, mas também na comunicação, seja ela a comunicação popular ou o jornalismo dos conglomerados de comunicação. Informando sobre os direitos, contribui-se para a construção da cidadania.

\section{Bibliografia:}

CANCLINI, Nestor García. «Consumidores e cidadãos: conflitos multiculturais da globalização». Tradução de Maurício Santana Dias. 5. ed. RJ: Editora UFRJ, 2005.

DAGNINO, Evelina. «Cultura, Cidadania e Democracia» - A transformação dos discursos e práticas na esquerda latino-americana. In: ALVAREZ, Sonia E; DAGNINO, Evelina; ESCOBAR, Arturo (org.). Cultura e política nos movimentos sociais latino-americanos: novas leituras. Belo Horizonte: Editora UFMG, 2000.

. «Os movimentos sociais e a emergência de uma nova noção de cidadania». In:

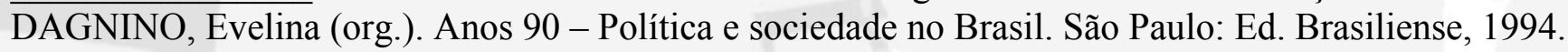

FAXINA, Élson. «Participação e Subjetividade em Movimentos Sociais»: um estudo de caso sobre as práticas culturais contemporâneas como espaço de construção e legitimação do ser individual e ator social. Dissertação de Mestrado. São Paulo: USP/ECA, 2001.

FESTA, Regina. «Comunicação popular e altenativa» - a realidade e as utopias. Dissertação de mestrado. São Bernardo do Campo, 1984.

GENTILLI, Victor. «Democracia de Massas»: Jornalismo e Cidadania: estudo sobre as sociedades contemporâneas e o direito dos cidadãos. Porto Alegre: EDIPUCRS, 2005.

GOHN, Maria da Glória. «Teoria dos movimentos sociais» - paradigmas clássicos e contemporâneos. São Paulo: Edições Loyola, 1997.

HELLER, Agnes. «O Cotidiano e a História». Trad. Carlos Nelson Coutinho e Leandro Konder, $3^{\mathrm{a}}$ ed. Rio de Janeiro: Paz e Terra, 1989.
LIMA, Venício
A.
«Comunicação,
Poder
e
Cidadania».
In: htpp://redebonja.cbj.g12/ielusc/necom/rastros/rastros07/rastros0701.pdf

MANZINI-COVRE, Maria de Lourdes. «O que é cidadania?» São Paulo: Brasiliense:1993. 
PERUZZO, Cicília Maria Krohling. «Comunicação nos movimentos Populares»: a participação na construção da cidadania. Petrópolis: Vozes, 1998.

. «A participação na comunicação popular». Tese de doutorado. São

Paulo: ECA/USP, 1991.

\section{Mini Currículo :}

Graduada em jornalismo pela Faculdade de Comunicação Social Cásper Líbero (2002), especialista em jornalismo social pela Cogeae (Coordenadoria Geral de Especialização, Aperfeiçoamento e Extensão) da PUC/SP (2006) e Mestranda em Ciências da Comunicação, no PPGCOM, da ECA/USP. Ingressou no Programa em 2007 e pesquisa a comunicação na Pastoral da Criança. 